\title{
Cell Individuality: The Bistable Gene Expression of the Type III Secretion System in Dickeya dadantii 3937
}

\author{
Quan Zeng, ${ }^{1}$ Michael D. Laiosa, ${ }^{2}$ Douglas A. Steeber, ${ }^{1}$ Eulandria M. Biddle, ${ }^{1}$ Quan Peng, ${ }^{1}$ and \\ Ching-Hong Yang ${ }^{1}$ \\ ${ }^{1}$ Department of Biological Sciences and ${ }^{2}$ School of Public Health, University of Wisconsin-Milwaukee 53211, U.S.A. \\ Submitted 2 May 2011. Accepted 17 August 2011.
}

\begin{abstract}
Dickeya dadantii 3937 is a gram-negative phytopathogenic bacterium that expresses genes encoding a type III secretion system (T3SS) in a bistable pattern when cultured in a homogeneous minimal media. In this work, we further characterized the bistable gene expression of T3SS at the single-cell level. We demonstrated that bistable expression of the HrpL-regulon genes, such as $h r p A$ and $h r p N$, is controlled by the same regulatory mechanism. We also showed that the expression level of the T3SS master regulatory gene $h r p L$ plays an important role in the development of the bistable expression of $h r p A$. A high expression level of $h r p L$ is required but unable to guarantee the high-state expression of $h r p A$ in a cell. In addition, bistable expression patterns of T3SS genes in other gram-negative pathogens of the Enterobacteriaceae and Pseudomonadaceae families were also described in this study. This suggests that the T3SS bistability might be a conserved population behavior in several gram-negative bacterial pathogens.
\end{abstract}

In a homogeneous bacterial population, the expression of a target gene in each individual cell is different. In most cases, a target gene is expressed in a monostable manner, showing a normal distribution pattern of expression: most cells in a bacterial population express the target gene at or around the average level, and some cells express the target gene slightly higher or lower than the average level. However, under certain circumstances, a target gene can also be expressed in a bistable manner. When bistable gene expression exists in a homogeneous bacterial population, a subpopulation of the cells expresses a target gene at a relatively higher level (high state), while the rest of the population expresses the target gene at a relatively lower level (low state) (Dubnau and Losick 2006; Veening et al. 2008). The bistable expression patterns are mostly found in the expression of genes related to bacterial survival, stress response, and virulence (Balaban et al. 2004; Chai et al. 2008; Maamar and Dubnau 2005; Veening et al. 2005). By expressing the stress-related genes in a bistable manner, bacteria increase their capability to adapt to the ever-changing environment and ability to survive in stressful conditions (Fraser and Kaern 2009).

The type III secretion system (T3SS) is a syringe-like structure that translocates effector proteins from bacteria cells di-

This work is dedicated to Noel T. Keen.

Corresponding author: C.-H. Yang; Telephone: +1 414.229.6331; Fax: +1 414.229.3926; E-mail: chyang@uwm.edu

* The $e$-Xtra logo stands for "electronic extra" and indicates that two supplementary figures are published online. rectly into eukaryotic host cells (Galan and Wolf-Watz 2006; Salmond and Reeves 1993). It is an important virulence factor of many gram-negative plant and animal pathogens, such as Dickeya dadantii, Pseudomonas syringae, P. aeruginosa, and Salmonella enterica. In our previous study, we discovered that, in $D$. dadantii, the expression of three T3SS genes in the HrpL-regulon, encoding a type III effector $(d s p E)$, a harpin protein $(h r p N)$, and a type III pilus ( $h r p A)$, show bistable gene expression in a homogeneous bacterial culture in vitro (Zeng et al. 2010). In a $D$. dadantii population, only a subpopulation expresses these T3SS genes at high-state level, while the rest of the population expresses the target gene at low-state level.

D. dadantii 3937 is a plant-pathogenic bacterium that causes soft rot, wilt, and blight diseases on a wide range of plant hosts (Agrios 1997; Pérombelon and Kelman 1980). It possesses two $h r p / d s p$ gene clusters that encode a functional T3SS required for the full virulence of this bacterium (Yang et al. 2002; Yap et al. 2005). The expression of genes encoding the type III secretion apparatus, harpins, and effector proteins is controlled by HrpL, an alternative $\sigma$ factor that binds to the conserved " $h r p$ box" region in the promoters of the HrpL regulon genes and activates their transcription (Tang et al. 2006). Expression of $h r p L$ is tightly controlled by multiple regulatory pathways: it is regulated by the HrpX-HrpY-HrpS-HrpL pathway at the transcriptional level and also modulated by the GacS-GacA-RsmB-RsmA pathway at the post-transcriptional level (Tang et al. 2006; Yang et al. 2008a and b; Yap et al. 2005).

Although bistable expression of $h r p A, h r p N$, and $d s p E$ has been observed in $D$. dadantii, the mechanism of how the bistable pattern develops is still unclear. In most reported cases, the bistable expression of a gene cluster is derived from the bistable expression of a master regulator of that gene cluster (Dubnau and Losick 2006; Grantcharova et al. 2010; Maamar and Dubnau 2005; Veening et al. 2005). By a mechanism of autostimulation and nonlinearity, in cells whose expression level of the master regulator gene is higher than a threshold level, the master regulator autostimulates its own expression and, thus, amplifies the noise to reach a high-state level of expression. Alternatively, in cells whose expression level of the master regulator gene is below the threshold, the autostimulation is not activated and, thus, the expression of the master regulatory gene remains low in the cell (Dubnau and Losick 2006; Ferrell 2002; Veening et al. 2008). For example, the Bacillus subtilis population divides into competent and noncompetent populations when entering stationary phase. The bistability of genes encoding proteins involved in genetic competence is initiated by the bistable expression of $\operatorname{com} K$, encoding the master regulator for competence development. Above a certain threshold level, ComK autostimulates its own expression by binding to 
the promoter of $\operatorname{com} K$, and this positive feedback regulation is essential for the development of the bistable expression of comK (Maamar and Dubnau 2005; Smits et al. 2005).

In this study, we examined the bistable expression of T3SS genes in $D$. dadantii. By using dual-fluorescence promoter reporter plasmids, we monitored the expression of two T3SS genes simultaneously at the single-cell level. The possible mechanism of T3SS bistability in $D$. dadantii was elucidated. We also showed that the bistable expression of T3SS is a common population behavior in several gram-negative bacterial pathogens.

\section{RESULTS}

The bistability of $h r p A, h r p N$, and $d s p E$ is not the result of the bistable expression of known T3SS regulatory genes.

In our previous study, bistable expression of HrpL regulon genes, such as $h r p A, h r p N$, and $d s p E$, was observed in a homogenous culture of $D$. dadantii 3937 using flow cytometry. To confirm the bistable expression of T3SS in $D$. dadantii, the $h r p A$ high-state and $h r p A$ low-state cell populations were separated using a florescence-activated cell sorter (FACS) according to the $h r p A$ promoter activity, and the mRNA levels of hrpA were compared in the sorted populations. A $2.567 \pm 0.28$ fold increase in the hrpA mRNA $(P<0.05)$ was observed in the $h r p A$ high-state cells compared with the $h r p A$ low-state cells. This confirms that the bistable expression of $h r p A$ observed in the promoter activity assay also occurs at the mRNA level.

In D. dadantii, the expression of $h r p A, h r p N$, and $d s p E$ are under the control of many T3SS regulators, including HrpL, HrpS, RpoN, RsmA, and RsmB. To elucidate the regulatory mechanism of the bistable expression of $h r p A, h r p N$, and
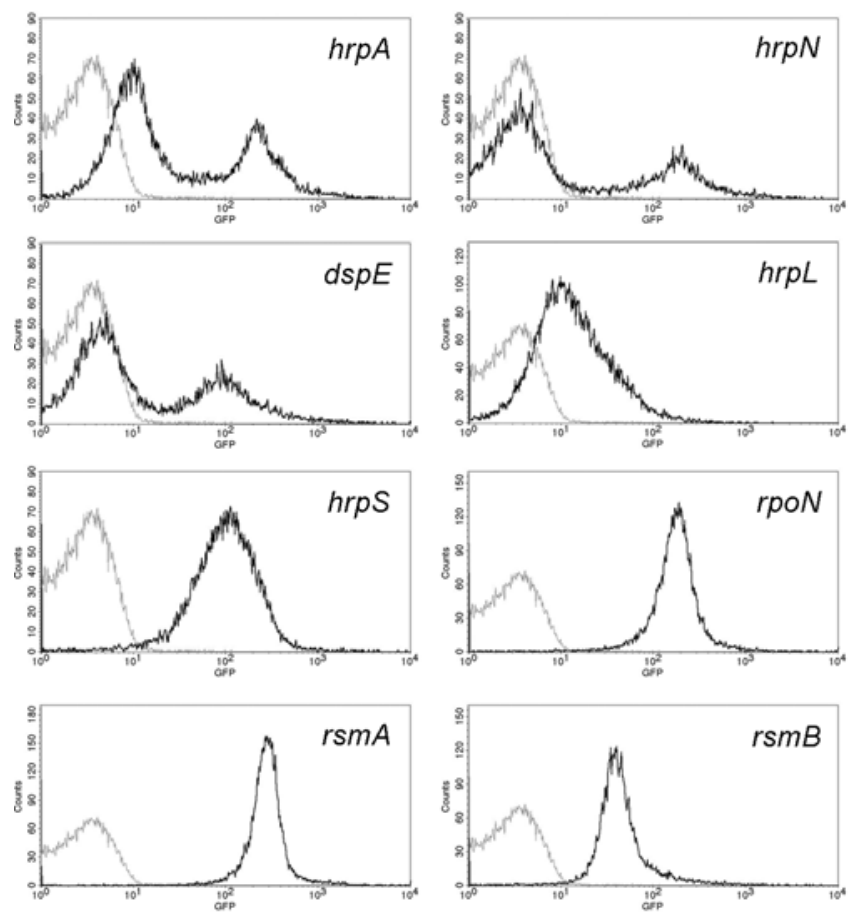

Fig. 1. Promoter activities of $h r p A, h r p N, d s p E, h r p L, h r p S, r p o N, r s m A$, and rsmB in Dickeya dadantii 3937. Cells carrying the promoter-probe plasmids were cultured in minimal medium for $12 \mathrm{~h}$, and the green fluorescent protein (GFP) intensity was measured by flow cytometry (BD FACSCalibur). The gray line indicates the GFP intensity in D. dadantii 3937 carrying empty vector pPROBE-AT, and the black line indicates the GFP intensities of $D$. dadantii 3937 carrying different promoter-reporter-derivative plasmids of pPROBE-AT. Similar results were observed in three independent experiments and the results of one experiment are shown here. $d s p E$, we cloned the promoters of $h r p L, h r p S, r p o N, r s m A$, and $r s m B$ into a promoter-green fluorescent protein $(g f p)$ reporter plasmid pPROBE-AT to test the expression patterns of these T3SS regulatory genes along with $h r p A, h r p N$, and $d s p E$ at the single-cell level. Consistent with our previous observation (Zeng et al. 2010), by using flow cytometry and fluorescence microscopy, bistable expression of $h r p A, h r p N$, and $d s p E$ was observed (Fig. 1; Supplementary Fig. S1). However, none of the T3SS regulatory genes tested showed a bistable gene expression pattern in $D$. dadantii (Fig. 1). This indicates that the bistability of $h r p A, h r p N$, and $d s p E$ may not directly originate from the bistability of a known T3SS regulatory gene at the transcriptional level.

\section{The bistability of $h r p A$ and $h r p N$ is controlled by the same regulatory mechanism.}

Using the promoter- $g f p$ reporter plasmid, the bistable expression of $h r p A, h r p N$, and $d s p E$ was observed in $D$. dadantii (Zeng et al. 2010) (Fig. 1). However, whether cells that are in $h r p A$ high state are also expressing $h r p N$ at the high-state level or, in other words, whether the bistable gene expression of $h r p A$ and $h r p N$ is initiated by the same regulatory mechanism, is not clear. To investigate this possibility, we developed a dual-fluorescence promoter reporter plasmid to simultaneously monitor the expression of $h r p A$ and $h r p N$ at the single-cell level (Fig. 2). The dual-fluorescence promoter reporter plasmid has the backbone of pPROBE-AT and contains an hrpA promoter- $m$ Cherry fusion and an hrpN promoter- $g f p$ fusion transcribed in opposite directions (Fig. 2). Thus, by detecting the fluorescence of mCherry and GFP, we are able to simultaneously monitor the expression of both $h r p A$ and $h r p N$ in the same group of cells. D. dadantii carrying plasmid pPhrpAPhrpN (Table 1) was cultured in minimal media (MM) and the expression of $m$ Cherry (representing $h r p A$ expression) and $g f p$ (representing $h r p N$ expression) was observed using fluorescence microscopy (Fig. 3A). Similar to our previous observation, bistable gene expression patterns of $h r p A$ and $h r p N$ were seen using the dual-fluorescence promoter reporter plasmid (Fig. 3A). Interestingly, we observed that, in a D. dadantii 3937

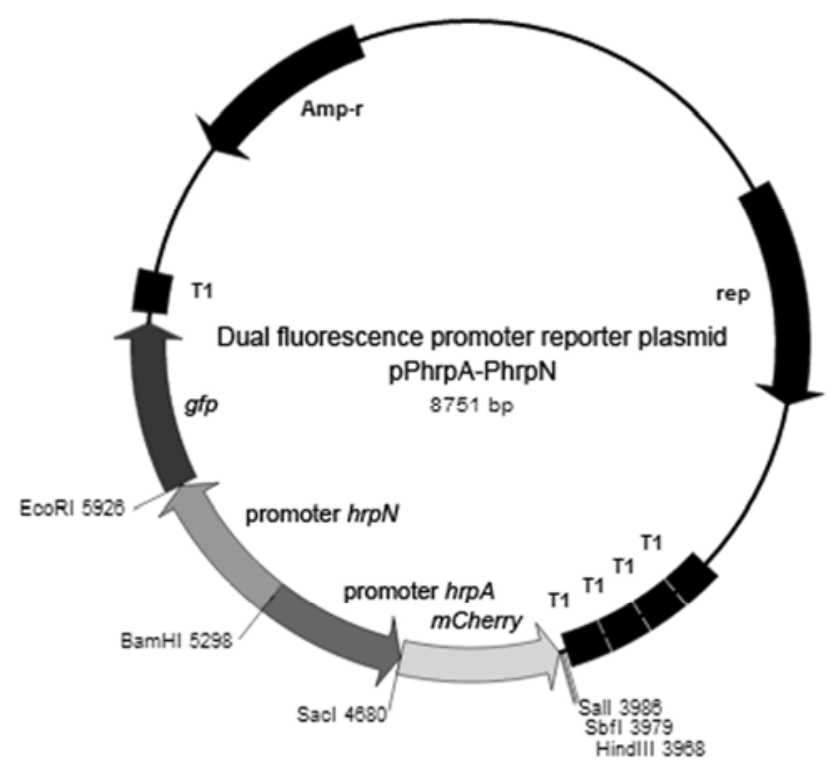

Fig. 2. Map of the dual-fluorescence promoter reporter plasmid pPhrpAPhrpN. This plasmid has a pPROBE-AT plasmid backbone (Miller et al. 2000). The locations of hrpA promoter, hrpN promoter, mCherry, gfp, terminators (T1), ampicillin-resistant gene (bla) and a gene required for replication (rep) are indicated. 
population, cells that highly express mCherry also highly express $g f p$; cells that are mCherry negative are also GFP negative. Similar results were observed using flow cytometry (Fig. 4, upper right panel). The fact that hrpA high-state cells are also $h r p N$ high-state cells and vice versa suggests that the bistable expression of the HrpL regulon genes, such as hrpA and $h r p N$, is controlled by the same regulator, which possibly initiates the bistable expression and passes the bistable expression pattern to the HrpL regulon genes.

\section{High expression level of $h r p L$ is required}

but cannot guarantee the high-state expression of $\boldsymbol{h r p A}$.

In $D$. dadantii 3937, $h r p A$ and $h r p N$ are two genes in the HrpL regulon. Because our results suggest that the bistable expression of $h r p A$ and $h r p N$ is controlled by the same regulator, and $\mathrm{HrpL}$ is the regulator that directly controls the expression of $h r p A$ and $h r p N$, the expression of $h r p L$ in tandem with the bistable expression of $h r p A$ was studied. We constructed a dual-fluorescence promoter reporter plasmid, pPhrpA-PhrpL, which carries two promoter-fluorescence gene fusions, PhrpAmCherry and PhrpL-gfp. D. dadantii 3937 carrying pPhrpAPhrpL was cultured in $\mathrm{MM}$ and the expression of $m$ Cherry (representing $h r p A$ expression) and gfp (representing $h r p L$ expression) was first examined by fluorescence microscopy.

A bistable gene expression of $h r p A$ and a monostable expression of $h r p L$ were observed in a $D$. dadantii population using pPhrpA-PhrpL (Fig. 3B). Interestingly, we observed that, in a population, cells expressing $h r p L$ at low level never expressed $h r p A$ in the high state (Fig. 3B), and cells that express $h r p A$ at high-state level always have a high level of $h r p L$ expression. However, not all cells expressing $h r p L$ at high level expressed $h r p A$ in high state (Fig. 3B, indicated by arrows). These results were also confirmed by flow cytometry. Using flow cytometry, we observed that, when the hrpL expression was below a certain threshold level (mean fluorescence intensity [MFI] approximately 100), the expression of hrpA did not reach the high-state level. However, cells expressing $h r p L$ above the threshold level (MFI approximately 100) could express $h r p A$ at either high state or low state. In fact, the $h r p L$ expression was over threefold higher in the $h r p A$ highstate cells than in the hrpA low-state cells (Fig. 4B, left). The expression of $r s m A$ in tandem with the bistable expression of $h r p A$ was also examined. A similar expression level of $r s m A$ was observed between hrpA high-state and low-state cells (Fig. $4 \mathrm{~B}$ right). In addition, the high-state and low-state cells of $h r p A$ are evenly distributed in a bacterial population expressing different levels of $r \operatorname{sm} A$. These results suggest that there is no correlation between $\operatorname{rsm} A$ expression and the bistability of hrpA. Together, the above results suggest that $\operatorname{HrpL}$ plays a role in determining whether a cell would express $h r p A$ in high state or low state. A high level of $h r p L$ is required but, nevertheless, cannot guarantee the high-state expression of $h r p A$ in a single cell.

\section{Bistable expression of $h r p A$ is not generated by positive feedback regulation through $h r p L$.}

So far, the only well-characterized mechanism for the generation of bistable gene expression is positive feedback regula-

Table 1. Bacterial strains and plasmids used in this study

\begin{tabular}{|c|c|c|}
\hline Strains and plasmids & Characteristics $^{\mathrm{a}}$ & $\begin{array}{l}\text { Reference or } \\
\text { source }\end{array}$ \\
\hline \multicolumn{3}{|l|}{ Strains } \\
\hline Dickeya dadantii 3937 & Wild-type strain of $D$. dadantii isolated from Saintpaulia ionantha & $\mathrm{HCP}^{\mathrm{b}}$ \\
\hline D. dadantii 3937::Ptet-hrpL & D. dadantii 3937 carrying Ptet-hrpL at rafB (ASAP19138) locus of the chromosome, $\mathrm{Cm}^{\mathrm{r}}$ & This work \\
\hline$\Delta h r p L::$ Ptet-hrpL & $\begin{array}{l}\text { hrpL deletion mutant of D. dadantii } 3937 \text { carrying Ptet-hrpL at rafB (ASAP19138) locus of the } \\
\text { chromosome, } \mathrm{Km}^{\mathrm{r}}, \mathrm{Cm}^{\mathrm{r}}\end{array}$ & This work \\
\hline \multicolumn{3}{|c|}{ 烈 } \\
\hline pTCLS-CM & $\begin{array}{l}\text { Plasmid used for chromosomal integration of gene construct to the rafB locus(ASAP19138) in } \\
\text { D. dadantii, } \mathrm{Ap}^{\mathrm{r}}, \mathrm{Cm}^{\mathrm{r}}\end{array}$ & Yap et al. 2008 \\
\hline pPROBE-AT & Promoter-probe vector, $\mathrm{Ap}^{\mathrm{r}}$ & Miller et al. 2000 \\
\hline PhrpA & pPROBE-AT derivative with PCR fragment containing $h r p A$ promoter region of $D$. dadantii, $\mathrm{Ap}^{\mathrm{r}}$ & Yang et al. 2008b \\
\hline PhrpN & pPROBE-AT derivative with PCR fragment containing $h r p N$ promoter region of $D$. dadantii, $\mathrm{Ap}^{\mathrm{r}}$ & Yang et al. $2008 \mathrm{~b}$ \\
\hline PdspE & pPROBE-AT derivative with PCR fragment containing $d s p E$ promoter region of $D$. dadantii, $\mathrm{Ap}^{\mathrm{r}}$ & Peng et al. 2006 \\
\hline PhrpL & pPROBE-AT derivative with PCR fragment containing $h r p L$ promoter region of $D$. dadantii, Ap ${ }^{\mathrm{r}}$ & Yang et al. 2007 \\
\hline PhrpS & pPROBE-AT derivative with PCR fragment containing $h r p S$ promoter region of $D$. dadantii, $\mathrm{Ap}^{\mathrm{r}}$ & Yang et al. 2008a \\
\hline PrpoN & pPROBE-AT derivative with PCR fragment containing rpoN promoter region of $D$. dadantii, Ap ${ }^{\mathrm{r}}$ & This work \\
\hline PrsmA & pPROBE-AT derivative with PCR fragment containing $r s m A$ promoter region of $D$. dadantii, $\mathrm{Ap}^{\mathrm{r}}$ & Zeng et al. 2010 \\
\hline PrsmB & pPROBE-AT derivative with PCR fragment containing $r s m B$ promoter region of $D$. dadantii, $\mathrm{Ap}^{\mathrm{r}}$ & This work \\
\hline phrpA $_{\text {carotovorum }}$ & $\begin{array}{l}\text { pPROBE-AT derivative with } \mathrm{PCR} \text { fragment containing } h r p A \text { promoter region of } \\
\text { Pectobacterium carotovorum, } \mathrm{Ap}^{\mathrm{r}}\end{array}$ & This work \\
\hline phrpA syringae $_{1}$ & pPROBE-AT derivative with PCR fragment containing $h r p A$ promoter region of & \\
\hline & Pseudomonas syringae, $\mathrm{Ap}^{\mathrm{r}}$ & This work \\
\hline phrpA $\mathrm{Amylovora}_{\text {a }}$ & $\begin{array}{l}\text { pPROBE-AT derivative with PCR fragment containing } h r p A \text { promoter region of } \\
\text { Erwinia amylovora, } \mathrm{Ap}^{\mathrm{r}}\end{array}$ & This work \\
\hline pexoS aeruginosa & $\begin{array}{l}\text { pPROBE-AT derivative with PCR fragment containing exoS promoter region of } \\
\text { P. aeruginosa, } \mathrm{Ap}^{\mathrm{r}}\end{array}$ & This work \\
\hline pmCherry-PnptII-gfp & Dual-fluorescence promoter reporter plasmid with $n p t I I$ promoter upstream of $g f p$ & This work \\
\hline pPnptII-mCherry-gfp & Dual-fluorescence promoter reporter plasmid with $n p t I I$ promoter upstream of $m$ Cherry & This work \\
\hline pPnptII-mCherry-PnptII-gfp & Dual-fluorescence promoter reporter plasmid with $n p t I I$ promoters upstream of both $g f p$ and $m$ Cherry & This work \\
\hline pPhrpA-PhrpN & $\begin{array}{l}\text { Dual-fluorescence promoter reporter plasmid carries transcriptional fusions of } h r p A \text { promoter- } \\
m C h e r r y \text { and } h r p N \text { promoter-gfp }\end{array}$ & This work \\
\hline pPhrpA-PhrpL & $\begin{array}{l}\text { Dual-fluorescence promoter reporter plasmid carries transcriptional fusions of } h r p A \text { promoter- } \\
m \text { Cherry and } h r p L \text { promoter-gfp }\end{array}$ & This work \\
\hline pPhrpA-PrsmA & $\begin{array}{l}\text { Dual-fluorescence promoter reporter plasmid carries transcriptional fusions of } h r p A \text { promoter- } \\
m \text { Cherry and } r s m A \text { promoter- } g f p\end{array}$ & This work \\
\hline
\end{tabular}


tion of the target gene (Dubnau and Losick 2006; Smits et al. 2006; Veening et al. 2008). Because the bistable expression of $h r p A$ and $h r p N$ is probably controlled by the same regulator, and HrpL is the master regulator of $h r p A$ and $h r p N$, we then tested whether HrpL autoregulates its own transcription, and whether the $h r p A$ expression remains bistable after removing the native promoter of $h r p L$.

To test whether HrpL autostimulates its own expression, a D. dadantii 3937::Ptet-hrpL strain was constructed by integrating an additional copy of $h r p L$ controlled by a tetracycline inducible promoter (Ptet) at the rafB (ASAP19138) locus of the chromosome of $D$. dadantii 3937 . The promoter activities of $h r p A, h r p L$, and $h r p S$ were measured in D. dadantii 3937 and D. dadantii 3937::Ptet-hrpL carrying pPhrpS or pPhrpL, respectively. Because Ptet is expressed at low levels even in the absence of the inducer tetracycline, the $h r p A$ expression is threefold higher in $D$. dadantii 3937::Ptet-hrpL strain than in D. dadantii 3937 (Fig. 5A). However, no significant alteration of $h r p L$ and $h r p S$ expression was observed between D. dadantii 3937 and D. dadantii 3937::Ptet-hrpL (Fig. 5A). This indicates that HrpL does not autoregulate its own expression or the expression of $h r p S$.

To further confirm that the bistable expression of $h r p A$ is not due to positive feedback regulation of $h r p L$, we constructed a strain in which the expression of $h r p L$ is independent of any internal regulation, $\Delta h r p L::$ Ptet-hrpL (Table 1). $\Delta$ hrpL::Ptet$h r p L$ is an $h r p L$ deletion mutant carrying a copy of the $h r p L$ gene controlled by Ptet integrated at the rafB (ASAP19138) locus of the chromosome. In the strain $\Delta$ hrpL::Ptet-hrpL, the expression of $h r p L$ is solely dependent on the concentration of tetracycline. Thus, if $h r p L$ is autoregulated, it would no longer be effective in this strain. Compared with the induced bistable gene expression of $h r p A$ in D. dadantii 3937::Ptet-hrpL, bistability of $h r p A$ was still observed in $\Delta$ hrpL::Ptet-hrpL (Fig. 5B). This result suggests that the bistable expression of the HrpL regulon genes is probably not due to autostimulation of hrpL. Finally, the Ptet promoter showed a monostable expression pattern. This was confirmed by cloning Ptet upstream of $g f p$ in the promoter reporter pPROBE-AT (data not shown).

\section{The bistable gene expression of T3SS is a conserved cellular behavior in many gram-negative bacterial pathogens.}

Because bistable expression patterns of the T3SS structural and functional genes were observed in $D$. dadantii, and the T3SS is a conserved virulence factor in many gram-negative bacterial pathogens, we investigated whether T3SS genes are also expressed in a bistable manner in other gram-negative bacteria species. The expression of genes encoding either a T3SS pilus or an effector protein in three other gram-negative plant bacterial pathogens (Pectobacterium carotovorum, $P$. syringae, and Erwinia amylovora) and one animal pathogen $(P$. aeruginosa) was assessed. Interestingly, using flow cytometry, we observed clear bistable gene expression patterns of the T3SS genes in all bacteria species tested (Fig. 6A). This indicates that the T3SS bistability in D. dadantii is not a unique case but, rather, a common behavior among different gram-negative bacteria. In addition, to understand whether the regulatory mechanism of the T3SS bistability is conserved among these gram-negative pathogens, we tested whether the $h r p A$ and $d s p E$ of $D$. dadantii would still be expressed in a bistable manner if expressed in a different gramnegative pathogen. Bistable expression of $D$. dadantii hrpA was observed when expressed in Pectobacterium carotovorum and E. amylovora. However, no expression of either $d s p E$ or $h r p A$ was observed when tested in $P$. syringae and $P$. aeruginosa (Fig. 6B).

\section{DISCUSSION}

Classical research methods to study the expression of a target gene, such as Northern blot and real-time reverse-transcription polymerase chain reaction (RT-PCR) assays, usually consider a bacterial population in a given condition as a uniform unit. However, these methods do not take into consideration that the expression of the target gene may be expressed at different levels among each individual cell within a bacterial population. With the advent of single-cell technologies, such as fluorescence microscopy and flow cytometry, the expression of a target gene in a bacterial population has been reviewed by several researchers (Avery 2006; Dubnau and Losick 2006; Smits et al. 2006; Veening et al. 2008). Using flow cytometry, our previous study discovered that, in $D$. dadantii, the expression of T3SS genes in the HrpL regulon, such as $h r p A, h r p N$, and $d s p E$, was bistable when cells were grown in a homogeneous medium (Zeng et al. 2010). In the present study, we first confirmed this observation by evaluating the transcription of $h r p A, h r p N$, and $d s p E$ in a bacterial population using fluorescence microscopy and by examining the mRNA levels of $h r p A$ in $h r p A$ high-state or low-state subpopulations that were separated by FACS. Our results showed that hrpA mRNA levels in high-state and low-state cell populations directly correspond to the bistable expression of the $h r p A$ promoter. We also assessed the viability of $D$. dadantii in the same in vitro culture condition by using the fluorescent, DNA-binding probe propidium iodide. Using flow cytometry, we detected that over $98 \%$ cells of a $D$. dadantii population $(50,000$ cells $)$ have intact cell envelopes (data not shown). This indicates that the low-state expression level observed within a population of cells that display bistable expression of T3SS genes is not due to cell death.

Bistable expression patterns of $h r p A$ and $h r p N$ were observed at the single-cell level in $D$. dadantii. The bistable expression of these two genes could either be derived from transcriptional noise of each individual gene or, rather, inherited from the bistable gene expression of a regulatory gene that controls the expression of both $h r p A$ and $h r p N$. From our results, it is unlikely that the bistability of $h r p A$ and $h r p N$ is generated at their own transcription. If the bistability of $h r p A$ and $h r p N$ is generated by random noise individually, the $h r p A$ high-state cells would not necessarily express $h r p N$ at high state. The fact that hrpA high-state cells are also $h r p N$ highstate cells and vice versa (Fig. 3A) suggests that the bistable expression of these two T3SS genes is generated extrinsically from a common regulator that regulates both $h r p A$ and $h r p N$. Based on previous studies of bistability in $B$. subtilis and $P$. aeruginosa (Maamar and Dubnau 2005; Turner et al. 2009), it is possible that, in $D$. dadantii, this common regulator may initiate the bistable gene expression pattern by an autostimulation mechanism, and pass the bistable expression to both $h r p A$ and $h r p N$, which it controls. Because all the T3SS regulatory genes ( $h r p L, h r p S, \operatorname{rpoN}, r s m A$, and $r s m B$ ) tested do not show bistable gene expression, it is possible that the bistabilities of $h r p A$ and $h r p N$ are probably not inherited from one of the known T3SS regulators at the transcriptional level. To exclude the possibility of cross-detection between GFP and mCherry, we tested the intensities of GFP and mCherry in cells carrying the dual-fluorescence promoter reporter with single transcriptional fusion nptII-mCherry or nptII-gfp (Supplementary Fig. S2). Our results showed that there is no GFP detected in cells carrying pPnptII-mCherry-gfp, and no mCherry detected in cells carrying pmCherry-PnptII-gfp.

Previous studies have demonstrated that the bistability of a gene cluster usually is derived from the bistable expression of a master regulatory gene (Chastanet et al. 2010; Chen et al. 
2009; Grantcharova et al. 2010). In B. subtilis, the bistabilities of genes involved in sporulation and competence are inherited from the bistable expression of spoOA and $\operatorname{comK}$, respectively (Chastanet et al. 2010; Chung et al. 1994; Maamar and Dubnau 2005; Veening et al. 2005). In P. aeruginosa, Turner and associates (2009) demonstrated that the expression of a set of virulence-related genes is bistable due to the bistable expression of an LysR-type transcription regulator of these virulence genes, bexR. In D. dadantii, HrpL is the T3SS master regulator that is known to regulate the transcription of $h r p A, h r p N$, and $d s p E$ (Tang et al. 2006). We showed that HrpL is not expressed in a bistable manner in a $D$. dadantii population (Fig. 1), nor does it have an autostimulation effect on its own expression (Fig. 5A). In $B$. subtilis, the bistability of competence genes becomes monostable when the autostimulation loop of ComK is broken (Maamar and Dubnau 2005). In our work, we eliminated the potential autostimulation loop of $h r p L$ by deleting the $h r p L$ gene and integrating a copy of Ptet-controlled $h r p L$ into the chromosome of the $\Delta h r p L$ strain, as previously described by Maamar and Dubnau (2005). Bistable expression of $h r p A$ was still observed in $\Delta$ hrpL::Ptet-hrpL, which confirms that, in contrast to $B$. subtilis and $P$. aeruginosa, in $D$. dadantii, the T3SS master regulatory gene $h r p L$ is probably not the origin of the bistable expression of $h r p A, h r p N$, and $d s p E$. The bistabilities of $h r p A, h r p N$, and $d s p E$ may originate from the bistability of an unidentified regulator that controls their expression.

It is worth noting that, although $h r p L$ does not show a bistable expression pattern, the levels of $h r p L$ expression varied greatly among individual cells (Fig. 3B) which may play a role in bistable expression of $h r p A$. A relatively higher expression noise was observed in $h r p L$ compared with that of $r \operatorname{smA}$ (Fig. 4A, lower right), whose variation of expression levels in a population was $2 \times 10^{3}$ to $9 \times 10^{4} \mathrm{MFI}$. The expression levels of $h r p L$ (Fig. 4A, lower left) were more diverse in a bacterial population $\left(0\right.$ to $\left.5 \times 10^{3} \mathrm{MFI}\right)$. As indicated by Eldar and Elowitz (2010), a bigger expression noise may be beneficial for the development of bistability. Although hrpL may not be the origin of the bistable expression of the $\mathrm{HrpL}$ regulon genes, our results demonstrate that the expression level of $h r p L$ in a cell still plays an important role in determining whether the cell would express the HrpL regulon genes at a high-state or low-state level. In order to express $h r p A$ at high-state level, our data suggest that the $h r p L$ expression level has to pass a threshold. Cells whose hrpL expression is below this threshold are not capable of expressing hrpA in high state (Fig. 7, upper panels), whereas cells whose hrpL expression is above this threshold would express $h r p A$ in either high state or low state (Fig. 7, lower panels). We propose that there might be an unidentified regulator or regulators controlling the bistable expression of $h r p A$. When $h r p L$ expression is above the threshold, the fate of high-state or low-state expression of $h r p A$ is determined by whether the unknown regulator is in high state or low state in that cell (Fig. 7, lower panels). Further work is needed to identify the unknown regulator of the T3SS bistability and to elucidate the role it plays in generating T3SS bistability in $D$. dadantii.

Although many reports have observed and characterized the bistable gene expression of genes related to bacterial stress responses, such as genetic competence, sporulation, biofilm formation, lactose utilization, and horizontal gene transfer, only a couple of them reported the bistable expression of genes related to virulence (Chai et al. 2008; Dubnau and Losick 2006; Grantcharova et al. 2010; Minoia et al. 2008; Veening et al. 2005). A recent paper by Turner and associates showed that some genes involved in the virulence of $P$. aeruginosa are expressed in a bistable manner (Turner et al. 2009). In Salmonella spp., the expression of $t c p A$, encoding the repeating subunit of toxin-coregulated pilus, is also bistable (Nielsen et al. 2010). It is interesting to observe that the T3SS is expressed in a bistable manner not only in $D$. dadantii but also in several other gram-negative bacteria species. This suggests that the T3SS bistability probably is a common population behavior in many gram-negative bacteria. The T3SSs are genetic apparatuses evolved and acquired independently by different gramnegative bacteria, presumably by horizontal transfer (Gophna et al. 2003; Nguyen et al. 2000). It is also suggested that the horizontal transmission of the genes encoding the T3SS in different bacteria species occurred in a conserved manner without

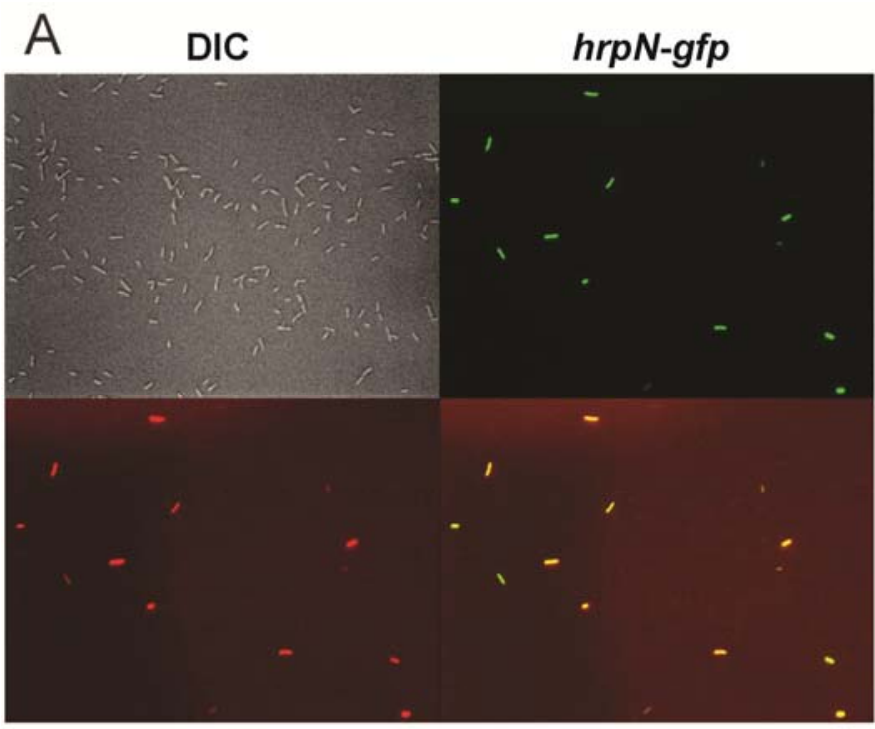

hrpA-mCherry
Overlay

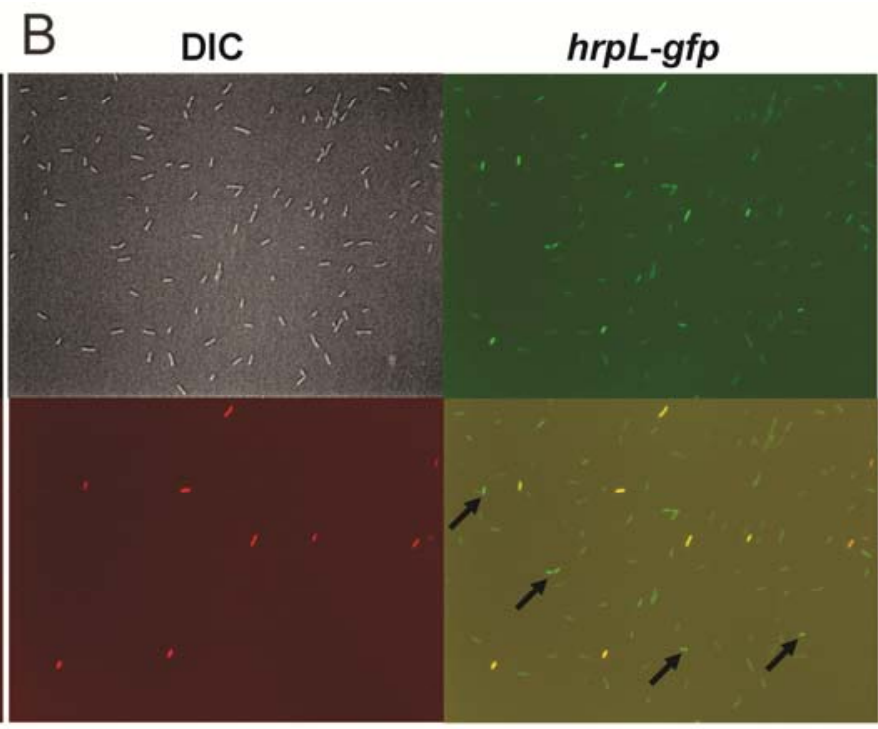

hrpA-mCherry
Overlay

Fig. 3. Fluorescence microscopic observation of Dickeya dadantii 3937 harboring A, pPhrpA-PhrpN and B, pPhrpA-PhrpL. D. dadantii 3937 carrying the dual-fluorescence promoter reporter plasmid was cultured in minimal medium for $12 \mathrm{~h}$. Differential interference contrast (DIC) light-microscopic observation (upper left panel), along with green fluorescence (upper right panel) and red fluorescence (lower left panel) were observed in the same group of cells. The lower right panel is the image overlay of the green fluorescence and red fluorescence. Similar results were observed in three independent experiments. 
the formation of hybrid gene clusters (Nguyen et al. 2000). It is possible that the bistability of T3SS may also be a conserved feature acquired during the bacterial evolution.

Many gram-negative pathogens use the T3SS as a major virulence factor during host infection. For plant pathogens such as $D$. dadantii and $P$. syringae, bacteria secrete effector proteins through the T3SS into host cells to dampen the host's defense machinery. However, secretion of type III effectors is a two-edged sword; they can also be recognized by plants and stimulate the host immune response. In their natural environment, bacteria may encounter diverse levels of plant-defense responses. It is possible that the bistable expression of T3SS which allows a proportion of the bacterial population in T3SS low state may keep a fraction of the bacterial cells to remain "T3SS dormant" while a portion of the bacterial cells are able to invade the plant host by expressing the T3SS at high state.
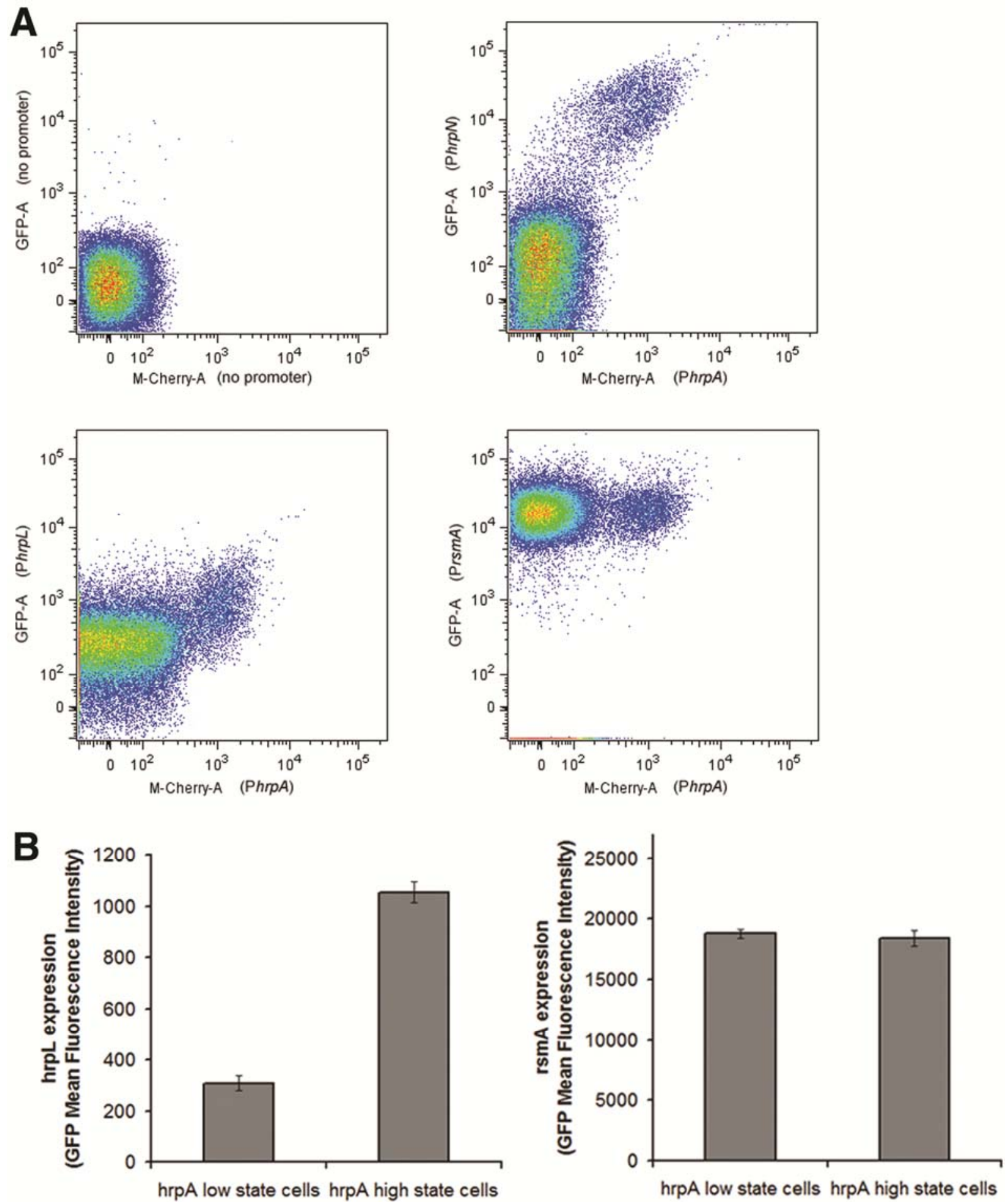

Fig. 4. A, Flow cytometry measurement of the red (M-Cherry-A) and green (GFP-A) fluorescence intensities of Dickeya dadantii 3937 harboring 1 , promoterless dual-fluorescence vector (upper left); 2, pPhrpA-PhrpN (upper right); 3, pPhrpA-PhrpL (lower left); and 4, pPhrpA-PrsmA (lower right). Cells were cultured in minimal medium at $28^{\circ} \mathrm{C}$ for $12 \mathrm{~h}$ and the green and red fluorescence intensities were measured by flow cytometry (FACSAria III). B, Promoter activities of $h r p L$ (left panel) and $r s m A$ (right panel) were compared in $h r p A$ high-state cells and in $h r p A$ low-state cells using flow cytometry (FACSAria III). Similar results were observed in three independent experiments. 
Once circumstances favor infection, more cells from the T3SS "dormant" population would easily be able to highly express T3SS; however, if conditions are unsuitable for infection, expression of T3SS would remain at low levels. Although the type II secretion is considered to be the major virulence factor in $D$. dadantii 3937 , the T3SS plays a role in pathogenicity during the initial stages of infection. The bistable expression of T3SS may be necessary for its virulence in plants and could be beneficial for the fitness of $D$. dadantii 3937 in the natural environment. Future work regarding the bistable expression of T3SS of $D$. dadantii 3937 in host plants would be an interesting prospect of study.

\section{MATERIALS AND METHODS}

Bacterial strains, plasmids, and culture conditions.

Bacterial strains and plasmids used in this study are listed in Table 1 . All bacteria strains were stored at $-80^{\circ} \mathrm{C}$ in $15 \%$ glyc-

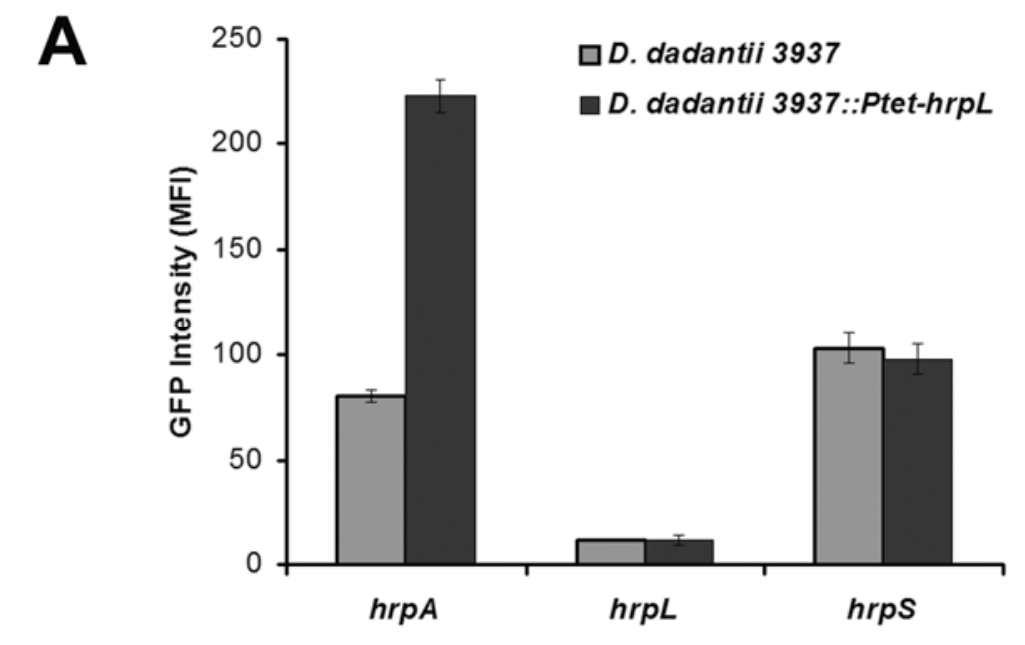

B

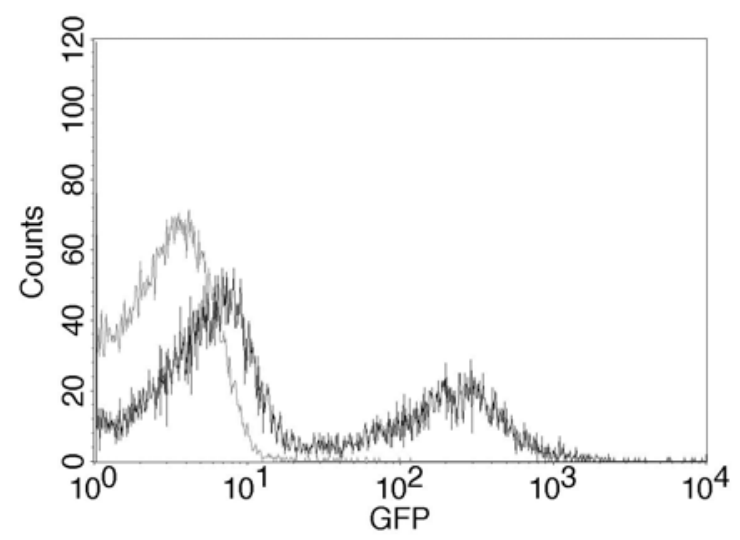

$\Delta h r p L:: P t e t-h r p L$

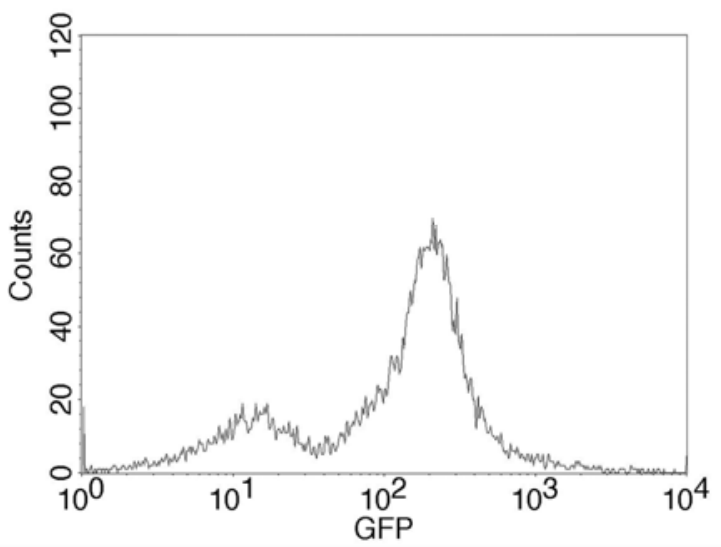

D. dadantii 3937::Ptet-hrpL

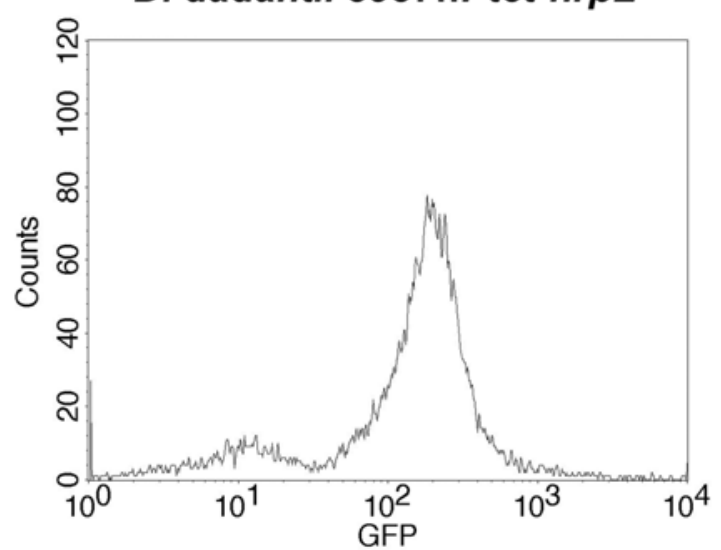

Fig. 5. A, Promoter activities of hrpA, hrpL and hrpS in Dickeya dadantii 3937 and D. dadantii 3937::Ptet-hrpL. B, Promoter activity and bistable expression pattern of $h r p A$ in D. dadantii 3937, D. dadantii 3937::Ptet-hrpL, and $\Delta h r p L::$ Ptet-hrpL. Bacteria strains carrying promoter-gfp reporter plasmids phrpA, phrpL, and phrpS were cultured in minimal medium for $12 \mathrm{~h}$, and the green fluorescent protein (GFP) intensities were measured by flow cytometry (FACSCalibur). Similar results were observed in three independent experiments. 
erol. D. dadantii strains, E. amylovora, and Pectobacterium carotovorum were cultured in Luria-Bertani (LB) medium or $\mathrm{MM}$ at $28^{\circ} \mathrm{C}$ with glucose as the carbon source (Yang et al. 2007). P. syringae was cultured in King's B medium or hrpinducing medium with fructose as the carbon source at $28^{\circ} \mathrm{C}$ (He et al. 1993). P. aeruginosa was cultured in MOPS minimal medium with $0.2 \%$ glucose, $5 \mathrm{mM}$ glutamate, $0.1 \%$ tryptone, and $10 \mathrm{mM}$ nitrilo-triacetic acid at $37^{\circ} \mathrm{C}$. When required, antibiotics were added to the media at the following concentrations: kanamycin, $50 \mu \mathrm{g} / \mathrm{ml}$; chloramphenicol, $30 \mu \mathrm{g} / \mathrm{ml}$; and ampicillin, $100 \mu \mathrm{g} / \mathrm{ml}$

\section{Construction of $D$. dadantii 3937::Ptet-hrpL and $\Delta$ hrpL::Ptet-hrpL.}

D. dadantii 3937::Ptet-hrpL and $\Delta$ hrpL::Ptet-hrpL were constructed by using a site-directed chromosomal insertion plasmid pTCLSCm, which carries the rafB-prt locus of $D$. dadantii 3937, a chloramphenicol resistance cassette, and an engineered multicloning site (Yap et al. 2008). A 1,480-bp fragment, Ptet-hrpL, containing the tetracycline inducible promoter Ptet fused with the $h r p L$ open reading frame (ORF) was constructed as follows: Ptet and hrpL ORF were PCR amplified using primers tet_F (5'-gctggtaccAAACGACGGCCAGT GAATTC-3') and tet_R (5'-gttctcgagAAAAGCTTGCATGCCT GCAG-3') (pALC2073 was used as the PCR template [Bateman et al. 2001], lowercase nucleotides represent the KpnI [ggtacc] and XhoI [ctcgag] recognition sites), and hrpL_F (5'-gctggtacc AATGGAAACGATTACACTGA-3') and hrpL_R (5'-gttctcgag GATTAAGGGAAGATGCCCTC-3'), respectively. The PCR fragments of Ptet and $h r p L$ were digested with KpnI and ligated, and Ptet-hrpL was generated by a recombinant PCR using the ligation product as template and hrpL_R and tet_R as primers. The fragment Ptet-hrpL was digested with XhoI, gel purified, and cloned into pTCLSCm. The resulting plasmid, pTCLS-Ptet-hrpL, was introduced into D. dadantii 3937 and $\Delta h r p L$ by electroporation. The transformants were grown in low-phosphate buffer medium $(100 \mathrm{mM}$ Tris base, $4 \mathrm{mM}$ $\mathrm{MgSO}_{4}, 7.57 \mathrm{mM}\left[\mathrm{NH}_{4}\right]_{2} \mathrm{SO}_{4}, 1.7 \mathrm{mM}$ sodium citrate, $250 \mathrm{mM}$ potassium phosphate buffer [pH 7.0], 0.2\% [wt/vol] glycerol, and $0.1 \%$ glucose) for $48 \mathrm{~h}$ at $28^{\circ} \mathrm{C}$, and double-crossover strains were selected by replica plating on LB plates in the presence or absence of ampicillin.

\section{Construction of the dual-fluorescence promoter reporter plasmids.}

The plasmid pPhrpA-PhrpL was constructed using the following method. The mCherry ORF, as well as the promoter regions of $h r p A$ and $h r p L$, were PCR amplified from pMEmCherry (Kwan et al. 2007) and the chromosome of $D$. dadantii 3937, respectively, using primers mCherry_F (5'-gttgagctcAAGGAGGAAAAACAT-ATGGTGAGCAAGGGCGAGGA-3', lowercase nucleotides represent the $S a c$ I [gagctc] recognition site, italic nucleotides represent a ribosomal binding site), mCherry_R (5'-gttgtcgacGGAAACAGCTATGACCATGT-3', lowercase nucleotides represent the SalI [gtcgac] site), hrpA_F (5'-gttggatccTCTACTTCCGGCTGGATACG-3', lowercase nucleotides represent the BamHI [ggatcc] site), hrpA_R (5'-ggtga gctcGATAAATATCTCCAGTTAAC-3', lowercase nucleotides represent the SacI [gagctc] site), hrpL_F (5'-ggtggatcc-GTCG GGTGTTTCGGGTTTT-3', lowercase nucleotides represent the BamHI [ggatcc] site), and hrpL_R (5'-gttgaatcc-TTCACTA ACTCTCCATCGAT-3', lowercase nucleotides represent the EcoRI [gaattc] site). The three PCR-amplified fragments $m$ Cherry, PhrpA, and PhrpL were purified and digested with
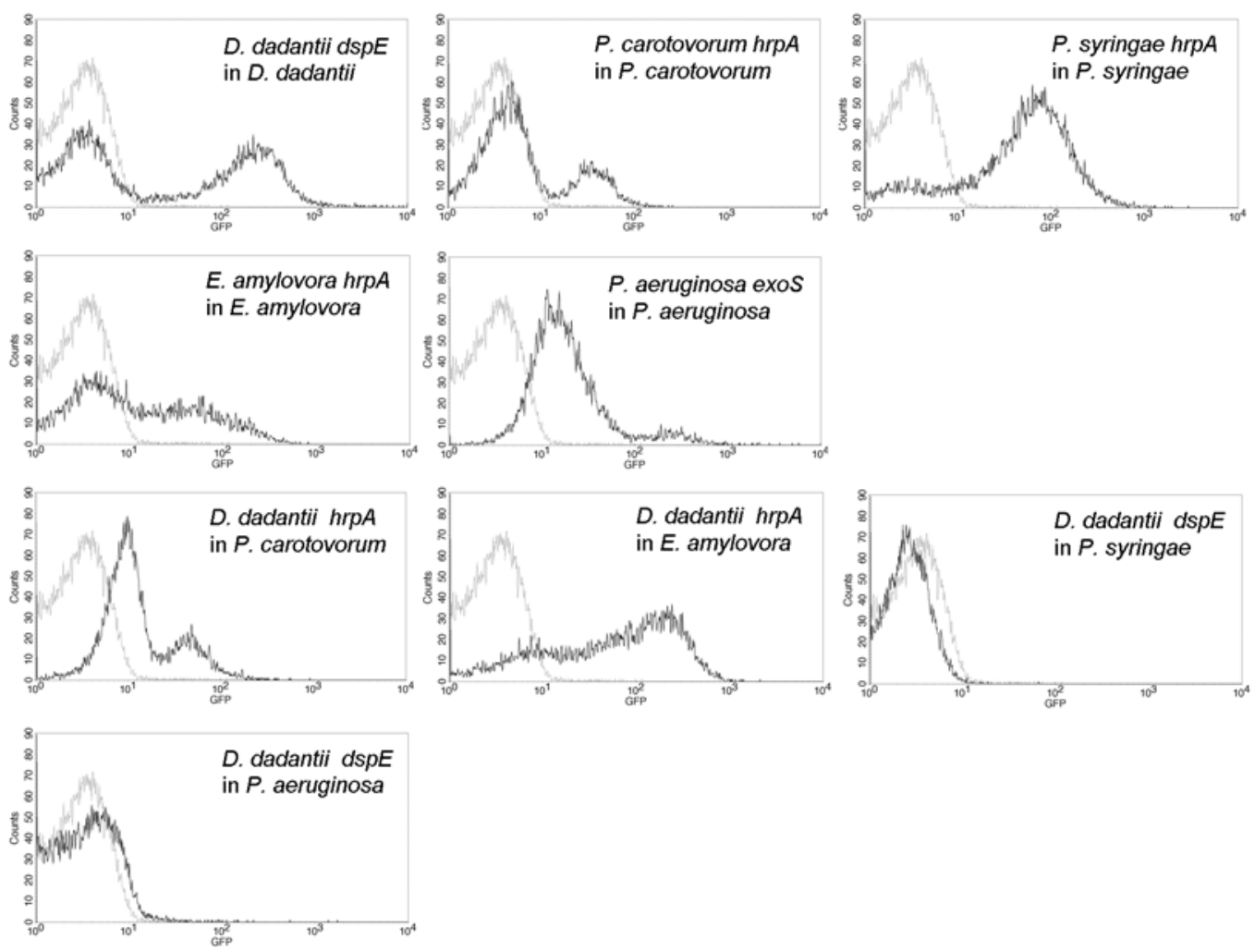

Fig. 6. A, Expression of Dickeya dadantii 3937 dspE, Pectobacterium carotovorum hrpA, Pseudomonas syringae hrpA, Erwinia amylovora hrpA, and P. aeruginosa exoS in D. dadantii3937, Pectobacterium carotovorum, Pseudomonas syringae, E. amylovora, and P. aeruginosa, respectively. B, Expression of D. dadantii 3937 hrpA in Pectobacterium carotovorum and in E. amylovora; and D. dadantii 3937 dspE in Pseudomonas syringae and P. aeruginosa. Promoters of the gene indicated were cloned into pPROBE-AT. The FACSCalibur flow cytometer was used for measuring bacteria green fluorescent protein (GFP) intensity during the early stationary phase of bacteria growth. Similar results were observed in three independent experiments. 
different restriction enzymes: SacI (mCherry), SacI and BamHI (PhrpA), and BamHI (PhrpL). The three fragments were then ligated and the recombinant DNA of mCherry-phrpA-phrpL was produced by PCR using the ligation product as PCR template and mCherry_R and hrpL_R as primers. The recombinant fragment $m$ Cherry-phrpA-phrpL was then digested with SalI and EcoRI, and cloned into the SalI-EcoRI site of plasmid pPROBE-AT which contains a $g f p$ gene downstream of the EcoRI site. The resulting plasmid, pPhrpA-PhrpL, carries PhrpA-mCherry and PhrpL-gfp fusions transcribed in opposite directions on a pPROBE-AT backbone (Fig. 1).

pPhrpA-PhrpN, pPhrpA-PrsmA, pmCherry-PnptII-gfp, pPnptII-mCherry-gfp, and pPnptII-mCherry-PnptII-gfp were cloned in a way similar to the method used to clone pPhrpAPhrpL, using the following primers: hrpN_F (5'-gatggattcCGA CCTGGTGTTTCAGTACG-3'), hrpN_R (5'-gccgaattcAATTT CGTTTCCTCATTCATGTC-3'), rsmA_F (5'-gatggattcGACC GATCGCGTCAAAGC-3'), rsmA_R (5' -gccgaattc-TCTTTGC TCCTTGAAAGATTAT-3'), PnptII_F (5'-TGTCAGCTACTG GGCTATCTG-3'), and PnptII_R (5'-TCACTGCCCCGGCTG AAGCGG-3').

\section{FACS assay.}

D. dadantii 3937 strains carrying different promoter reporter plasmids were cultured in $\mathrm{MM}$ at $28^{\circ} \mathrm{C}$ for $12 \mathrm{~h}$. Cells were collected by centrifugation, washed with $1 \times$ phosphate-buffered saline (PBS) $(8.0 \mathrm{~g}$ of $\mathrm{NaCl}, 0.2 \mathrm{~g}$ of $\mathrm{KCl}, 1.44 \mathrm{~g}$ of $\mathrm{Na}_{2} \mathrm{HPO}_{4}$, and $0.24 \mathrm{~g}$ of $\mathrm{KH}_{2} \mathrm{PO}_{4}$ per liter; $\mathrm{pH} 7.2$ to 7.4 ), and resuspended in PBS at $10^{6} \mathrm{CFU} / \mathrm{ml}$.

The GFP intensities of $D$. dadantii 3937 carrying promoter$g f p$ fusion plasmids were measured by a four-color flow cytometry (FACSCalibur; BD Biosciences, San Jose, CA, U.S.A.) equipped with 488- and 633-nm lasers. Bacteria were electronically gated based on forward and side light-scatter properties. Total GFP fluorescence intensity was measured using the 488-nm laser and the FL1 channel on the gated population. In total, 20,000 cells were analyzed for each sample. The results were analyzed using CellQuest Pro software (BD Biosciences).

The GFP and mCherry intensities of $D$. dadantii carrying dual-fluorescence promoter reporter plasmids were measured using a BD FACSAria III flow cytometer (BD Biosciences) equipped with a forward-scatter photomultiplier tube (PMT) installed on the Blue Laser detector array. Bacteria were electronically gated based on forward-scatter PMT and side-scatter distribution. Total GFP emission intensity was measured following 488-nm blue laser excitation detected using the Blue B detector with a $502 \mathrm{LP}$ and 530/30 filter. Total mCherry emission intensity was measured using the yellow-green 561-nm laser excitation, detected using the using the yellow-green $\mathrm{C}$ detector with a $600 \mathrm{LP}$ and 610/20 filter. In total, 50,000 cells
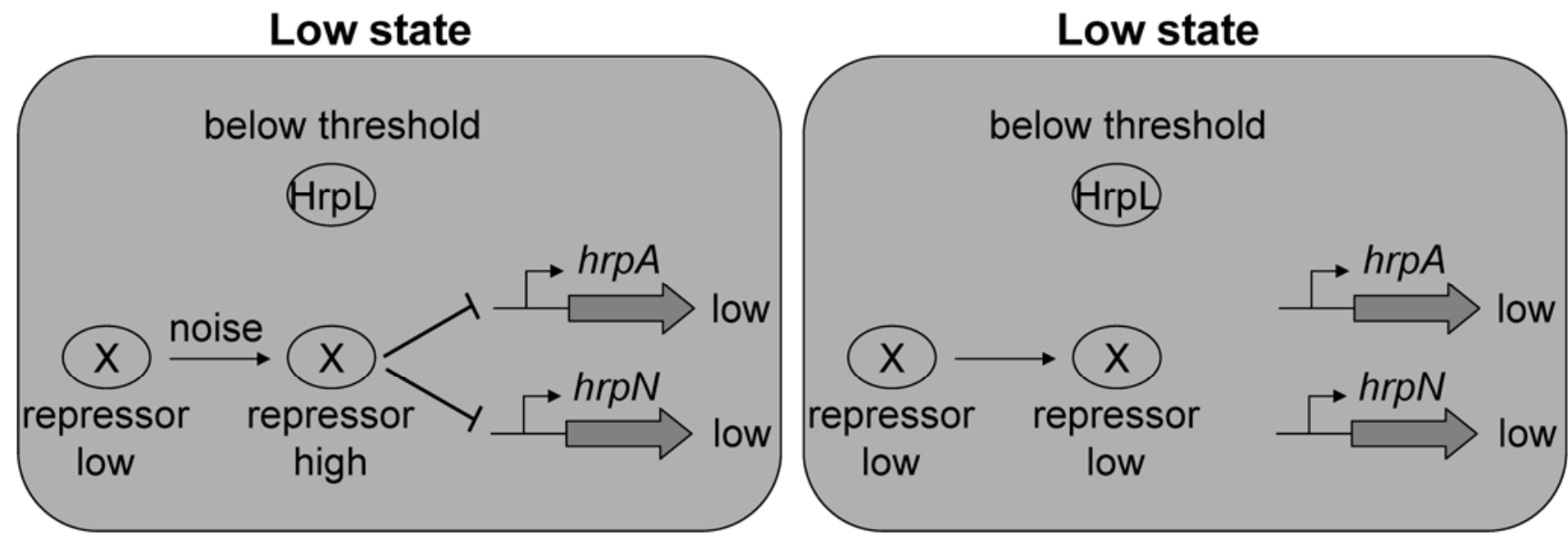

Low state

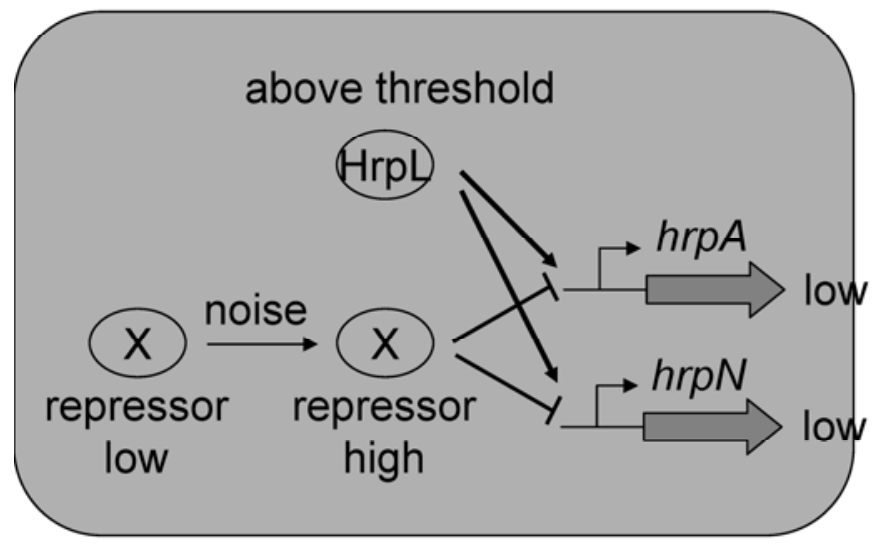

High state

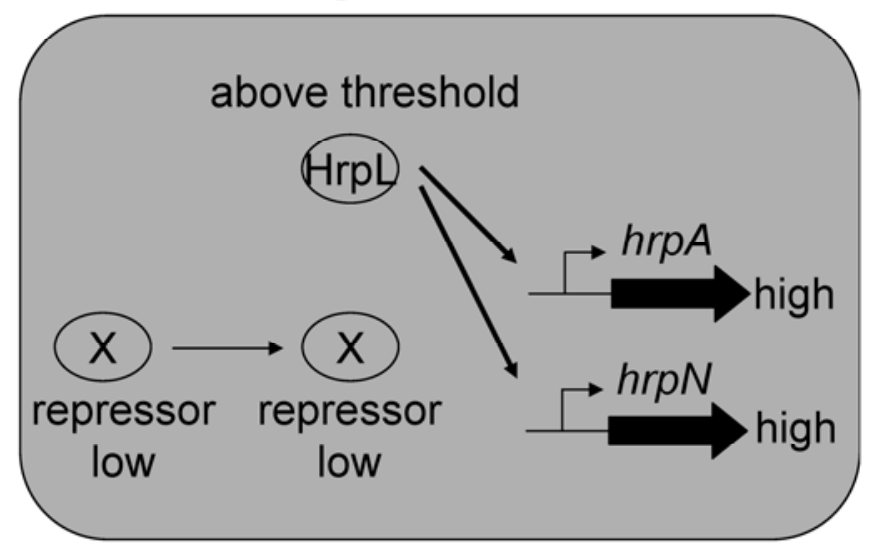

Fig. 7. Working model of $h r p A / h r p N$ bistability in Dickeya dadantii. Expression of $h r p A$ and $h r p N$ is regulated by HrpL and an unknown regulator (we hypothesize it as repressor X). Repressor X has a mechanism to amplify the gene expression noise and initiate the bistable expression, which gives rise to the bistability of $h r p A$ and $h r p N$. In cells whose HrpL level is below a particular threshold, the expression of $h r p A$ and $h r p N$ cannot be activated; thus, those cells will express $h r p A$ and $h r p N$ at low-state level despite the level of repressor $\mathrm{X}$ in the cell (upper left and upper right). In cells whose HrpL level is above the threshold, the HrpL level is high enough to bind to the promoters of $h r p A$ and $h r p N$ and activate their expression to the high-state level. However, whether those cells will actually become high-state cells is determined by the cellular level of repressor X. Cells in which repressor X level is low and HrpL level is above the threshold would express the type III secretion system (T3SS) in high state (lower right), while cells whose repressor X level is high would express T3SS in low state despite a high expression level of $h r p L$ (lower left). 
were analyzed for each sample. The results were analyzed using FlowJo software (Treestar, Ashland, OR, U.S.A.).

\section{Fluorescence microscopy.}

D. dadantii 3937 carrying different promoter reporter plasmids were cultured in $\mathrm{MM}$ at $28^{\circ} \mathrm{C}$ for $12 \mathrm{~h}$. Wet mount slides were prepared by applying cells to agarose-coated microscope slides to observe live but immobile cells. Briefly, $5 \mu \mathrm{l}$ of melted $1 \%$ agarose was applied on top of a microscope slide and air dried. Next, $2 \mu \mathrm{l}$ of cell culture was applied to the agarose-coated slide and covered by a cover slip. Cells were observed under a Nikon TE 2000-U epifluorescence microscope equipped with a CoolSnap ES digital camera (Photometrics, Tucson, AZ, U.S.A.). Differential interference contrast light microscopic images, along with green and red fluorescence, were observed for the same microscopic field. Digital monochromatic images were captured, pseudocolored, and overlayed using Metamorph software (Universal Imaging Corp, Downingtown, PA, U.S.A.).

\section{FACS sorting, RNA isolation, and real-time RT-PCR.}

D. dadantii 3937 carrying phrpA was cultured in MM at $28^{\circ} \mathrm{C}$ for $12 \mathrm{~h}$. Cells were collected by centrifugation, washed with $1 \times$ PBS $\left(8.0 \mathrm{~g}\right.$ of $\mathrm{NaCl}, 0.2 \mathrm{~g}$ of $\mathrm{KCl}, 1.44 \mathrm{~g}$ of $\mathrm{Na}_{2} \mathrm{HPO}_{4}$, and $0.24 \mathrm{~g}$ of $\mathrm{KH}_{2} \mathrm{PO}_{4}$ per liter; $\mathrm{pH} 7.2$ to 7.4 ) three times, and resuspended in PBS at $10^{4} \mathrm{CFU} / \mathrm{ml}$. The GFP fluorescence signals were measured using the BD FACSAria III flow cytometer. Bacteria were electronically gated based on forward-scatter PMT and side-light-scatter properties. GFP fluorescence was measured following 488-nm blue laser excitation detected using the Blue B detector with a 502 LP and 530/30 filter. hrpA high-state cells (GFP MFI greater than 110) and low-state cells (GFP MFI less than 11) were sorted into two tubes containing RNAlater Solution (Ambion, Austin, TX, U.S.A.).

Total bacterial RNA was isolated by using the TRI reagent method (Sigma-Aldrich, St. Louis) and treated with Turbo DNA-free DNase (Ambion). cDNA was synthesized from 0.5 $\mu \mathrm{g}$ of DNase-treated total RNA using the iScript cDNA Synthesis Kit (Bio-Rad, Hercules, CA, U.S.A.). The RealMasterMix SYBR ROX (5 PRIME, Gaithersburg, MD, U.S.A.) was used for real-time PCR reactions to quantify the cDNA levels of target genes. rplU was used as an endogenous control for data analysis (Kuchma et al. 2005; Mah et al. 2003). Data were collected by the Opticon 2 system (Bio-Rad) and analyzed using the Relative Expression Software Tool as described by Pfaffl and associates (Pfaffl et al. 2002).

\section{ACKNOWLEDGMENTS}

We thank A. Udvadia for providing pME-mCherry; P. Lakatos for his help with flow cytometry and cell sorting; and G. Singh, J. Yang, and K. D. Timm for assistance on promoter activity assay. This project was supported by grants from the National Science Foundation (award number EF-0332163), the Research Growth Initiative of the University of Wisconsin-Milwaukee (UWM), the Catalyst Grant in advanced Automation of UWM Research Foundation, and the Undergraduate Research Fellows (SURF) awarded to K. D. Timm.

\section{LITERATURE CITED}

Agrios, G. N. 1997. Plant Pathology, fourth edition, Academic Press, New York.

Avery, S. V. 2006. Microbial cell individuality and the underlying sources of heterogeneity. Nat. Rev. Microbiol. 4:577-587.

Balaban, N. Q., Merrin, J., Chait, R., Kowalik, L., and Leibler, S. 2004 Bacterial persistence as a phenotypic switch. Science 305:1622-1625.

Bateman, B. T., Donegan, N. P., Jarry, T. M., Palma, M., and Cheung, A. L. 2001. Evaluation of a tetracycline-inducible promoter in Staphylococcus aureus in vitro and in vivo and its application in demonstrating the role of
sigB in microcolony formation. Infect. Immun. 69:7851-7857.

Chai, Y., Chu, F., Kolter, R., and Losick, R. M. 2008. Bistability and biofilm formation in Bacillus subtilis. Mol. Microbiol. 67:254-263.

Chastanet, A., Vitkup, D., Yuan, G. C., Norman, T. M., Liu, J. S., and Losick, R. M. 2010. Broadly heterogeneous activation of the master regulator for sporulation in Bacillus subtilis. Proc. Natl. Acad. Sci. U.S.A. 107:8486-8491.

Chen, R., Guttenplan, S. B., Blair, K. M., and Kearns, D. B. 2009. Role of the sigmaD-dependent autolysins in Bacillus subtilis population heterogeneity. J. Bacteriol. 191:5775-5784.

Chung, J. D., Stephanopoulos, G., Ireton, K., and Grossman, A. D. 1994 Gene expression in single cells of Bacillus subtilis: Evidence that a threshold mechanism controls the initiation of sporulation. J. Bacteriol. 176:1977-1984.

Dubnau, D., and Losick, R. 2006. Bistability in bacteria. Mol. Microbiol 61:564-572.

Eldar, A., and Elowitz, M. B. 2010. Functional roles for noise in genetic circuits. Nature 467:167-173.

Ferrell, J. E., Jr. 2002. Self-perpetuating states in signal transduction: Positive feedback, double-negative feedback and bistability. Curr. Opin. Cell Biol. 14:140-148.

Fraser, D., and Kaern, M. 2009. A chance at survival: Gene expression noise and phenotypic diversification strategies. Mol. Microbiol. 71:1333-1340.

Galan, J. E., and Wolf-Watz, H. 2006. Protein delivery into eukaryotic cells by type III secretion machines. Nature 444:567-573.

Gophna, U., Ron, E. Z., and Graur, D. 2003. Bacterial type III secretion systems are ancient and evolved by multiple horizontal-transfer events. Gene 312:151-163.

Grantcharova, N., Peters, V., Monteiro, C., Zakikhany, K., and Romling, U. 2010. Bistable expression of CsgD in biofilm development of Salmonella enterica serovar typhimurium. J. Bacteriol. 192:456-466.

He, S. Y., Huang, H. C., and Collmer, A. 1993. Pseudomonas syringae pv. syringae harpinPss: A protein that is secreted via the Hrp pathway and elicits the hypersensitive response in plants. Cell 73:1255-1266.

Kuchma, S. L., Connolly, J. P., and O'Toole, G. A. 2005. A three-component regulatory system regulates biofilm maturation and type III secretion in Pseudomonas aeruginosa. J. Bacteriol. 187:1441-1454.

Kwan, K. M., Fujimoto, E., Grabher, C., Mangum, B. D., Hardy, M. E., Campbell, D. S., Parant, J. M., Yost, H. J., Kanki, J. P., and Chien, C. B. 2007. The Tol2kit: A multisite gateway-based construction kit for Tol2 transposon transgenesis constructs. Dev. Dynam. 236:3088-3099.

Maamar, H., and Dubnau, D. 2005. Bistability in the Bacillus subtilis Kstate (competence) system requires a positive feedback loop. Mol. Microbiol. 56:615-624.

Mah, T. F., Pitts, B., Pellock, B., Walker, G. C., Stewart, P. S., and O'Toole, G. A. 2003. A genetic basis for Pseudomonas aeruginosa biofilm antibiotic resistance. Nature 426:306-310.

Miller, W. G., Leveau, J. H., and Lindow, S. E. 2000. Improved $g f p$ and inaZ broad-host-range promoter-probe vectors. Mol. Plant-Microbe Interact. 13:1243-1250

Minoia, M., Gaillard, M., Reinhard, F., Stojanov, M., Sentchilo, V., and van der Meer, J. R. 2008. Stochasticity and bistability in horizontal transfer control of a genomic island in Pseudomonas. Proc. Natl. Acad. Sci. U.S.A. 105:20792-20797.

Nguyen, L., Paulsen, I. T., Tchieu, J., Hueck, C. J., and Saier, M. H. Jr. 2000. Phylogenetic analyses of the constituents of Type III protein secretion systems. J. Mol. Microbiol. Biotechnol. 2:125-144.

Nielsen, A. T., Dolganov, N. A., Rasmussen, T., Otto, G., Miller, M. C., Felt, S. A., Torreilles, S., and Schoolnik, G. K. 2010. A bistable switch and anatomical site control Vibrio cholerae virulence gene expression in the intestine. PLoS Pathog. 6:e1001102. Published online.

Pérombelon M., and Kelman A. 1980. Ecology of the soft rot erwinias. Ann. Rev. Phytopathol. 18:361-387.

Pfaffl, M. W., Horgan, G. W., and Dempfle, L. 2002. Relative expression software tool (REST) for group-wise comparison and statistical analysis of relative expression results in real-time PCR. Nucleic Acids Res. 30:e36. Published online.

Salmond, G. P., and Reeves, P. J. 1993. Membrane traffic wardens and protein secretion in gram-negative bacteria. Trends Biochem. Sci. 18:7-12.

Smits, W. K., Eschevins, C. C., Susanna, K. A., Bron, S., Kuipers, O. P., and Hamoen, L. W. 2005. Stripping Bacillus: ComK auto-stimulation is responsible for the bistable response in competence development. Mol. Microbiol. 56:604-614.

Smits, W. K., Kuipers, O. P., and Veening, J. W. 2006. Phenotypic variation in bacteria: The role of feedback regulation. Nat. Rev. Microbiol. 4:259-271.

Tang, X., Xiao, Y., and Zhou, J. M. 2006. Regulation of the type III secretion system in phytopathogenic bacteria. Mol. Plant-Microbe Interact. 19:1159-1166. 
Turner, K. H., Vallet-Gely, I., and Dove, S. L. 2009. Epigenetic control of virulence gene expression in Pseudomonas aeruginosa by a LysR-type transcription regulator. PLoS Genet. 5:e1000779. Published online.

Veening, J. W., Hamoen, L. W., and Kuipers, O. P. 2005. Phosphatases modulate the bistable sporulation gene expression pattern in Bacillus subtilis. Mol. Microbiol. 56:1481-1494.

Veening, J. W., Smits, W. K., and Kuipers, O. P. 2008. Bistability, epigenetics, and bet-hedging in bacteria. Annu. Rev. Microbiol. 62:193210

Yang, C. H., Gavilanes-Ruiz, M., Okinaka, Y., Vedel, R., Berthuy, I., Boccara, M., Chen, J. W., Perna, N. T., and Keen, N. T. 2002. hrp genes of Erwinia chrysanthemi 3937 are important virulence factors. Mol. Plant-Microbe Interact. 15:472-480.

Yang, S., Zhang, Q., Guo, J., Charkowski, A. O., Glick, B. R., Ibekwe, A. M., Cooksey, D. A., and Yang, C. H. 2007. Global effect of indole-3acetic acid biosynthesis on multiple virulence factors of Erwinia chrysanthemi 3937. Appl. Environ. Microbiol. 73:1079-1088.
Yang, S., Peng, Q., San Francisco, M., Wang, Y., Zeng, Q., and Yang, C. H. 2008a. Type III secretion system genes of Dickeya dadantii 3937 are induced by plant phenolic acids. PLoS One 3:e2973. Published online.

Yang, S., Peng, Q., Zhang, Q., Yi, X., Choi, C. J., Reedy, R. M., Charkowski, A. O., and Yang, C. H. 2008b. Dynamic regulation of GacA in type III secretion, pectinase gene expression, pellicle formation, and pathogenicity of Dickeya dadantii (Erwinia chrysanthemi 3937). Mol. PlantMicrobe Interact. 21:133-142.

Yap, M. N., Yang, C. H., Barak, J. D., Jahn, C. E., and Charkowski, A. O. 2005. The Erwinia chrysanthemi type III secretion system is required for multicellular behavior. J. Bacteriol. 187:639-648.

Yap, M. N., Yang, C. H., and Charkowski, A. O. 2008. The Response regulator HrpY of Dickeya dadantii 3937 regulates virulence genes not linked to the hrp cluster. Mol. Plant-Microbe Interact. 21:304-314.

Zeng, Q., Ibekwe, A. M., Biddle, E., and Yang, C. H. 2010. Regulatory mechanisms of exoribonuclease PNPase and regulatory small RNA on T3SS of Dickeya dadantii. Mol. Plant-Microbe Interact. 23:1345-1355. 